\title{
Macrophage-derived exosomes attenuate the susceptibility of oral squamous cell carcinoma cells to chemotherapeutic drugs through the AKT/GSK-3ß pathway
}

\author{
RIKI TOMITA, ERI SASABE, AYUMI TOMOMURA and TETSUYA YAMAMOTO \\ Department of Oral and Maxillofacial Surgery, Kochi Medical School, Kochi University, Nankoku, Kochi 783-8505, Japan
}

Received October 25, 2019; Accepted July 10, 2020

DOI: $10.3892 /$ or.2020.7748

\begin{abstract}
Although chemotherapy is initially effective in debulking tumor mass in a number of different types of malignancy, tumor cells gradually acquire chemoresistance and frequently progress to advanced clinical stage. Accumulating evidence has indicated that the tumor sensitivity to several chemotherapeutic drugs is regulated by tumor stromal cells including macrophages. However, the role of macrophages in the efficacy of chemotherapeutics on oral squamous cell carcinoma (OSCC) cells is poorly understood. In the present study, the effects of macrophage-secreted exosomes on the sensitivity of OSCC cells towards chemotherapeutic agents were examined. Specifically, the effects of exosomes derived from THP-1 cells and primary human macrophages (PHM) were assessed on the chemosensitivity of OSC-4 cells treated with 5-fluorouracil (5-FU) and cis-diamminedichloroplatinum (CDDP). The THP-1- and PHM-derived exosomes promoted dose-dependent proliferation, decreased the proliferative inhibitory effects of 5-FU and CDDP and decreased apoptosis in OSC-4 cells through activation of the AKT/glycogen synthase kinase-3 $\beta$ signaling pathway. LY294002, a PI3K inhibitor, and MK-2206, an AKT inhibitor, were both able to suppress the observed decrease in sensitivity to chemotherapeutic agents induced by exosomes. Overall, the data from the present study suggested that the macrophage-derived exosomes may decrease the sensitivity to chemotherapeutic agents in OSCC cells. Thus, targeting the interaction between OSCC cells and macrophage-derived exosomes may be considered as a therapeutic approach to improve the chemosensitivity of the tumor microenvironment in oral cancer.
\end{abstract}

Correspondence to: Mr. Riki Tomita, Department of Oral and Maxillofacial Surgery, Kochi Medical School, Kochi University, 185-1 Kohasu, Oko-cho, Nankoku, Kochi 783-8505, Japan E-mail: jm-rikitomita@kochi-u.ac.jp

Key words: exosome, macrophage, oral squamous cell carcinoma, chemotherapeutic drugs, AKT

\section{Introduction}

Worldwide, oral cancer accounts for $>650,000$ cases and 330,000 deaths annually (1). Oral squamous cell carcinoma (OSCC) comprises $>90 \%$ of all types of oral cancer. Despite recent therapeutic advances, OSCC has a significant recurrence rate and metastasizes to cervical lymph nodes in $\sim 40 \%$ of the patients (2). Although chemotherapeutic agents including 5-fluorouracil (5-FU) and cis-diamminedichloroplatinum (CDDP) are frequently used as induction, adjuvant, neoadjuvant or palliative therapy in patients with advanced-stage OSCC, achieving complete remission by chemotherapy alone is extremely difficult. Additionally, in certain patients, an initial decrease in tumor size is followed by a gradual progression to an aggressive behavior and worse clinical outcome through the acquisition of chemoresistance by tumor cells (3). However, the molecular mechanisms underlying the acquisition of chemoresistance in OSCC cells are not fully understood.

Several studies have reported that stromal cells within the tumor microenvironment including macrophages and fibroblasts are involved in the acquisition of resistance to chemotherapeutic agents by cancer cells (4-6). Tumor-associated macrophages (TAMs) infiltrate and accumulate in the tumor microenvironment to promote tumor growth through the induction of angiogenesis and extracellular remodeling; TAMs also suppress antitumor immunity through the secretion of various factors, including growth and pro-angiogenic factors, matrix-degrading enzymes and immunosuppressive cytokines (7). Additionally, previous studies have reported that TAMs also induce chemoresistance against 5-FU and CDDP through the release of cytokines, chemokines, microRNAs and inorganic compounds (8-12). The frequently observed TAM infiltration of the OSCC tissue specimens and the reported relationship between TAMs and cancer progression (13-15), suggest that TAMs might also regulate the chemosensitivity of OSCC cells.

Exosomes, which are small membrane vesicles released by a variety of mammalian cells into the extracellular space, are taken up by the recipient cells affecting their function and activity through their cargo, which include lipids, proteins and nucleic acids that come from the cell of origin (16-19). We also previously reported that OSCC cell-derived exosomes can be taken up by the OSCC cells themselves promoting 
tumor progression through the activation of the PI3K/AKT, mitogen-activated protein kinase/extracellular signal-regulated kinase (ERK) and c-jun N-terminal kinase 1/2 pathways (20). These reports suggest that within the tumor microenvironment, exosomes secreted from the stromal cells, including those released from the TAMs, may also be involved in chemotherapy failure in OSCC (16-20). However, the role of TAM-derived exosomes in the regulation of chemoresistance in OSCC has not been fully elucidated. The present study investigated the influence of TAM-derived exosomes on the malignant potential and chemosensitivity of OSCC cells, as well as the mechanisms underlying the contribution of TAM-derived exosomes in the progression of OSCC in order to elucidate molecular mechanisms underlying the acquisition of chemoresistance in OSCC cells.

\section{Materials and methods}

Cell culture and reagents. The OSC-4 cells, which were established in our laboratory using a sample from a patient with tongue cancer, were cultured in Dulbecco's modified Eagle's medium (DMEM) (Nissui Pharmaceutical Co., Ltd.) supplemented with $10 \%(\mathrm{v} / \mathrm{v})$ fetal bovine serum (FBS), $10 \mathrm{mM}$ glutamine, $100 \mathrm{U} / \mathrm{ml}$ penicillin and $100 \mu \mathrm{g} / \mathrm{ml}$ streptomycin (all from Gibco; Thermo Fisher Scientific, Inc.) at $37^{\circ} \mathrm{C}$ in a humidified $5 \% \mathrm{CO}_{2}$ air atmosphere (21). This patient provided written informed consent at the time when the original study and establishment of the cell line was conducted. The human monocytic THP-1 cells, derived from a patient with acute monocytic leukemia, were obtained from the American Type Culture Collection and cultured in Roswell Park Memorial Institute (RPMI)-1640 medium (Nissui Pharmaceutical Co., Ltd.) supplemented with $10 \%$ (v/v) FBS, $10 \mathrm{mM}$ glutamine, $100 \mathrm{U} / \mathrm{ml}$ penicillin and $100 \mu \mathrm{g} / \mathrm{ml}$ streptomycin at $37^{\circ} \mathrm{C}$ in a humidified $5 \% \mathrm{CO}_{2}$ air atmosphere. THP-1 cells $\left(1 \times 10^{6}\right.$ cells $\left./ \mathrm{ml}\right)$ were differentiated into macrophages by treatment with $200 \mathrm{ng} / \mathrm{ml}$ phorbol 12-myristate 13-acetate (PMA) (Sigma Aldrich; Merck KGaA) for 24 h at $37^{\circ} \mathrm{C}$. Peripheral blood mononuclear cells (PBMC) were isolated from peripheral blood of eight healthy adults from Kochi University Hospital (Nankoku, Japan) between October 2018 and March 2020 using Ficoll-Paque Plus (GE Healthcare Life Sciences), according to the manufacturer's instructions. The mean age was $32.2 \pm 8.1$ years, $50 \%$ were female and $50 \%$ were male. Primary human monocytes (PHMs) from human PBMCs were isolated using anti-CD14 monoclonal antibody-coated microbeads (Miltenyi Biotec, Inc.), and were differentiated into macrophages through culture in RPMI-1640 medium supplemented with $5 \mathrm{ng} / \mathrm{ml}$ granulocyte-macrophage colony-stimulating factor (PeproTech, Inc.) for 7 days. The 5-FU and CDDP were obtained from Sigma-Aldrich; Merck KGaA. LY294002 and MK-2206 were purchased from ChemScene, LLC. OSC-4 cells were treated with $10 \mu \mathrm{M}$ LY294002 or $10 \mu \mathrm{M}$ MK-2206 for $24 \mathrm{~h}$ in each experiment.

Exosome isolation. THP-1 cells and PHMs were cultured in RPMI-1640 medium supplemented with 5\% (v/v) exosome-depleted FBS (System Biosciences, LLC) for $48 \mathrm{~h}$, and the exosomes were isolated using the Total Exosome Isolation kit (Invitrogen; Thermo Fisher Scientific, Inc.) according to the manufacturer's protocol. Briefly, the cell culture supernatants were collected and centrifuged at 2,000 x g for $30 \mathrm{~min}$ at room temperature to remove cells and cell debris. Next, the total exosome isolation kit reagent was added to the supernatants and the mixture was refrigerated at $4^{\circ} \mathrm{C}$ overnight. The mixture was centrifuged at $10,000 \mathrm{xg}$ for $60 \mathrm{~min}$ at $4^{\circ} \mathrm{C}$ to remove the supernatants. The pellets containing the exosomes were resuspended in phosphate-buffered saline (PBS), and the protein concentrations were determined using the bicinchoninic acid (BCA) assay.

Exosome labeling and cellular uptake. The purified exosomes were labeled with PKH26 or PKH67 (Sigma-Aldrich; Merck KGaA) according to the manufacturer's protocol. Briefly, $1 \mu \mathrm{l}$ PKH26 or PKH67 was added to $100 \mu \mathrm{g}$ of the exosome pellets in a total volume of $400 \mu \mathrm{l}$ diluent $\mathrm{C}$ and incubated for $5 \mathrm{~min}$ at room temperature. The labeling reaction was stopped by adding an equal volume of $1 \%$ bovine serum albumin (Sigma Aldrich; Merck KGaA), and the samples were ultra-centrifuged at $10,000 \mathrm{x} \mathrm{g}$ for 60 $\min$ at $4^{\circ} \mathrm{C}$. The supernatants were removed, and the pellets were resuspended in PBS.

To assess cellular uptake of the PKH26-labeled exosomes by confocal laser microscopy, a total of $1 \times 10^{4}$ cells/well OSC-4 cells were first cultured in Nunc Lab-Tek 8-well chamber slides (Thermo Fisher Scientific, Inc.) for $24 \mathrm{~h}$ to achieve complete adhesion. Next, the cells were treated with $10 \mu \mathrm{g} / \mathrm{ml}$ PKH26-labeled exosomes for $24 \mathrm{~h}$. After the incubation, cells were washed twice with PBS and mounted with SlowFade Diamond Antifade Mountant with DAPI. The images were captured using a Fluoview FV-1000D confocal laser scanning microscope at x400 magnification.

To assess cellular uptake of the exosomes by flow cytometry, a total of $1 \times 10^{5}$ cells/well OSC- 4 cells were cultured in 12-well microplates for $24 \mathrm{~h}$ to achieve complete adhesion. Next, the cells were treated with $10 \mu \mathrm{g} / \mathrm{ml}$ PKH67-labeled exosomes for 0, 2, 4, 8, 12 and $24 \mathrm{~h}$ at $37^{\circ} \mathrm{C}$. After the incubation, cells were washed twice with PBS and analyzed on a FACScan cytometer using FlowJo software (version 10; BD Biosciences). Each experiment was performed in triplicate.

Protein extraction and western blot analysis. OSC-4 cells were treated with $50 \mu \mathrm{g} / \mathrm{ml}$ THP-1- or PHM-derived exosomes in the presence or absence of $100 \mu \mathrm{M}$ chemotherapeutic drugs, $10 \mu \mathrm{M}$ LY294002 or MK-2206 for $24 \mathrm{~h}$. Then, the total cell lysates from cell cultures and proteins from the THP-1- and PHM-derived exosomes were collected by radioimmunoprecipitation assay buffer $(50 \mathrm{mM}$; Tris $\mathrm{pH} 7.4$, $150 \mathrm{mM}$ NaCI, $1 \mathrm{mM}$ EDTA, $0.25 \%$ sodium deoxycholate, $1.0 \%$ NP-40 and protease inhibitors). The protein concentrations were determined using a BCA assay. The extracted proteins (50 $\mu \mathrm{g} /$ lane) were separated by SDS-PAGE and transferred to PVDF membranes. The membranes were blocked in Tris-buffered saline containing 5\% (w/v) skimmed milk powder and $0.1 \%(\mathrm{v} / \mathrm{v})$ Tween-20 at $4^{\circ} \mathrm{C}$ overnight. The membranes were then probed with the primary antibodies against CD9 (1:1,000; cat. no. ab92726; Abcam), CD63 (1:1,000; cat. no. sc-5275; Santa Cruz Biotechnology, Inc.), Ras-related protein Rab-5B (Rab5B; 1:1,000; cat. 
no. sc-598; Santa Cruz Biotechnology, Inc.), calnexin (1:200; cat. no. MAB3126; EMD Millipore), cytochrome C (1:1,000; cat. no. 556433; BD Biosciences), phosphorylated (Ser473) Akt (p-AKT; 1:200; cat. no. cs4060; Cell Signaling Technology, Inc.), AKT (1:500; cat. no. cs4691; Cell Signaling Technology, Inc.), phosphorylated (Ser21/9) glycogen synthase kinase-3 $\beta$ (GSK-3 $\beta$ ) (p-GSK-3 $\beta ; 1: 500$; cat. no. cs9327; Cell Signaling Technology, Inc.), GSK-3 $\beta$ (1:500; cat. no. cs9315; Cell Signaling Technology, Inc.), and $\beta$-actin (1:500; cat. no. ab8226; Abcam). The signals were incubated for $1 \mathrm{~h}$ at room temperature with horseradish peroxidase (HRP)-conjugated anti-mouse IgG secondary antibody (cat. no. NA9310) or HRP-conjugated anti-rabbit IgG secondary antibody (cat. no. NA9340) (both 1:2,000; both from GE Healthcare). The signal detection was performed using and enhanced chemiluminescence system (GE Healthcare).

Proteome profiling. The Human Chemokine Array C1 (RayBiotech, Inc.) was used to measure chemokine levels within the exosomes. Briefly, $100 \mu \mathrm{g}$ exosomes were lysed in lysis buffer and analyzed according to the manufacturer's instructions. The densitometric analysis of the arrays was performed using the Multi Gauge (version 3.11; Fuji Film).

Cell proliferation assay. Cell proliferation was analyzed using standard cell counting and the Cell Counting Kit-8 (CCK-8; Dojindo Molecular Technologies, Inc.) assay. For cell counting, a total of $5 \times 10^{4}$ cells/well OSC- 4 cells were seeded in 12-well culture plates and cultured for $24 \mathrm{~h}$ at $37^{\circ} \mathrm{C}$, followed by incubation with $50 \mu \mathrm{g} / \mathrm{ml}$ THP-1- or PHM-derived exosomes for 24,48 and $72 \mathrm{~h}$. Thereafter, cells were trypsinized and counted using a hemocytometer. For the CCK-8 assay, a total of $5 \times 10^{3}$ cells/well OSC-4 cells were seeded in 96-well culture plates and cultured for $24 \mathrm{~h}$, followed by incubation with THP-1 and PHM-derived conditioned medium (CM) (1:10 ratio, v/v) or increasing concentrations of THP-1- or PHM-derived exosomes in the presence or absence of $100 \mu \mathrm{M} 5$-FU or CDDP for $24 \mathrm{~h}$. Then, $10 \mu \mathrm{l}$ of CCK-8 solution was added to each well and the cells were incubated for an additional $2 \mathrm{~h}$ at $37^{\circ} \mathrm{C}$ and the absorbance was measured at $450 \mathrm{~nm}$ using a microplate reader. Each experiment was performed in triplicate.

Migration assay. The migratory potential of the cells was examined using the CytoSelect 24-well cell migration assay (Cell Biolabs, Inc.). Briefly, a total of $2.5 \times 10^{5}$ cells/well OSC-4 cells were seeded in 24-well plates containing proprietary treated plastic inserts and maintained in culture for $24 \mathrm{~h}$. The inserts were then removed, and the cells were treated with increasing concentrations of THP-1- or PHM-derived exosomes for $10 \mathrm{~h}$ at $37^{\circ} \mathrm{C}$. After staining with $0.5 \%$ crystal violet in $10 \%$ ethanol for 10 mins at room temperature, the percentage of closure in the wound field was determined by light microscopy at x40 magnification. Each experiment was performed in triplicate.

Invasion assay. The invasive potential of the cells was evaluated using the BioCoat Matrigel Invasion Chamber kit (BD Biosciences). Briefly, the OSC-4 cells at a density of $7.5 \times 10^{4}$ cells $/ 500 \mu 1$ were added to the Transwell insert chamber containing a filter coated with Matrigel. In the lower compartment, $750 \mu$ l DMEM containing 10\% FBS was used as the chemoattractant. The OSC-4 cells were incubated with increasing concentrations of THP-1- or PHM-derived exosomes for $24 \mathrm{~h}$ at $37^{\circ} \mathrm{C}$. The inserts were removed and non-invading cancer cells remaining on the upper side of the filter were scraped off. Cells that invaded the lower side of the filter were then stained with the Diff-Quick solution (Sysmex Corporation) at room temperature for 10 mins and light microscopically observed and counted in five randomly selected fields, at x200 magnification. Each experiment was performed in triplicate.

Apoptosis assay. The OSC-4 cells were incubated with $50 \mu \mathrm{g} / \mathrm{ml}$ THP-1- or PHM-derived exosomes in the presence or absence of $100 \mu \mathrm{M} \mathrm{5-FU}$ or CDDP for $24 \mathrm{~h}$ at $37^{\circ} \mathrm{C}$. Next, the cells were stained with propidium iodide (PI) and FITC-conjugated annexin V and analyzed on a FACScan cytometer using FlowJo software (version 10; BD Biosciences). Each experiment was performed in triplicate.

Cell cycle analysis. The cell cycle status was determined by flow cytometric analysis of PI-stained cells. The cells were treated with $50 \mu \mathrm{g} / \mathrm{ml}$ THP-1- or PHM-derived exosomes in the presence or absence of $100 \mu \mathrm{M} 5-\mathrm{FU}$ or CDDP for $24 \mathrm{~h}$ at $37^{\circ} \mathrm{C}$, fixed with $70 \%$ ethanol for $1 \mathrm{~h}$ at $4^{\circ} \mathrm{C}$, and treated with $0.5 \mathrm{mg} / \mathrm{ml} \mathrm{RNase} \mathrm{A} \mathrm{for} 30 \mathrm{~min}$ at $37^{\circ} \mathrm{C}$. Next, the cells were stained with $20 \mu \mathrm{g} / \mathrm{ml} \mathrm{PI}$ and analyzed on a FACScan cytometer using FlowJo. Each experiment was performed in triplicate.

Statistical analysis. The data are presented as the mean \pm standard deviation. Statistical differences among the experimental conditions were performed using one-way analysis of variance (ANOVA) or two-way ANOVA followed by Tukey's multiple comparisons test. All statistical analyses were performed using BellCurve for Excel (Social Survey Research Information Co., Ltd.) and $\mathrm{P}<0.05$ was considered to indicate a statistically significant difference.

\section{Results}

THP-1- and PHM-derived exosomes are taken up by the OSC-4 cells. First, a western blot analysis was performed in order to characterize the THP-1- and PHM-derived exosomes. CD9, CD63 and Rab5B, which are used as exosomal markers, were expressed on the THP-1- and PHM-derived exosomes (Fig. 1A). Conversely, calnexin and cytochrome $\mathrm{C}$ were not detectable in the exosomal lysates (Fig. 1A). Next, the THP-1 and PHM-derived exosomes were treated with PKH26 and PKH67, two fluorescent dyes with long aliphatic tails that are incorporated into the lipid membrane of exosomes, to study the uptake of the isolated exosomes. Following the incubation of OSC-4 cells with the PKH26-labeled THP-1- or PHM-derived exosomes, the presence of $\mathrm{PKH} 26$-positive granules in the cytoplasm of OSC-4 cells was observed by confocal laser microscopy; the granules were more diffuse at $24 \mathrm{~h}$ compared with their distribution at $4 \mathrm{~h}$ after the addition (Fig. 1B). 
A
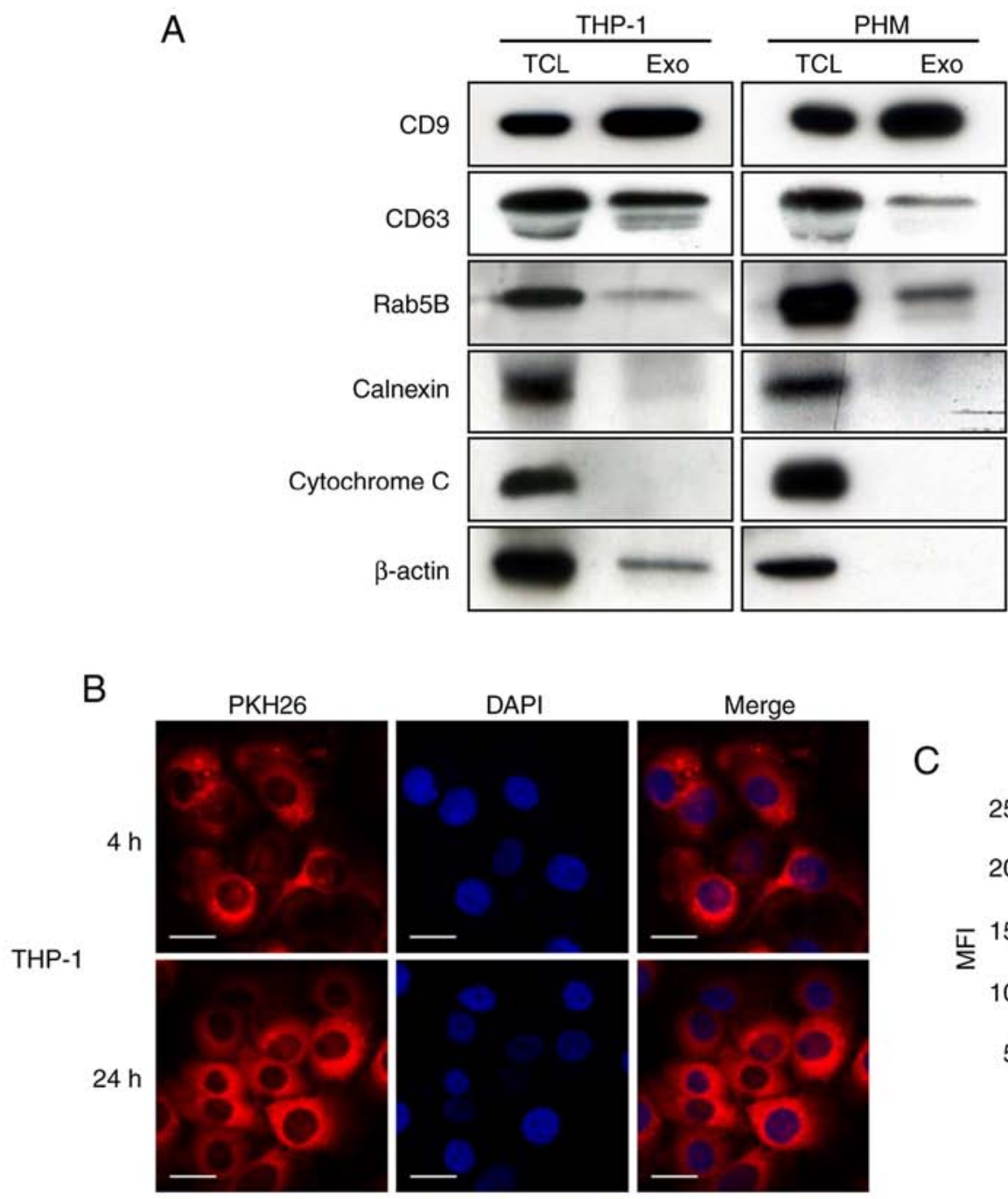

C

THP-1
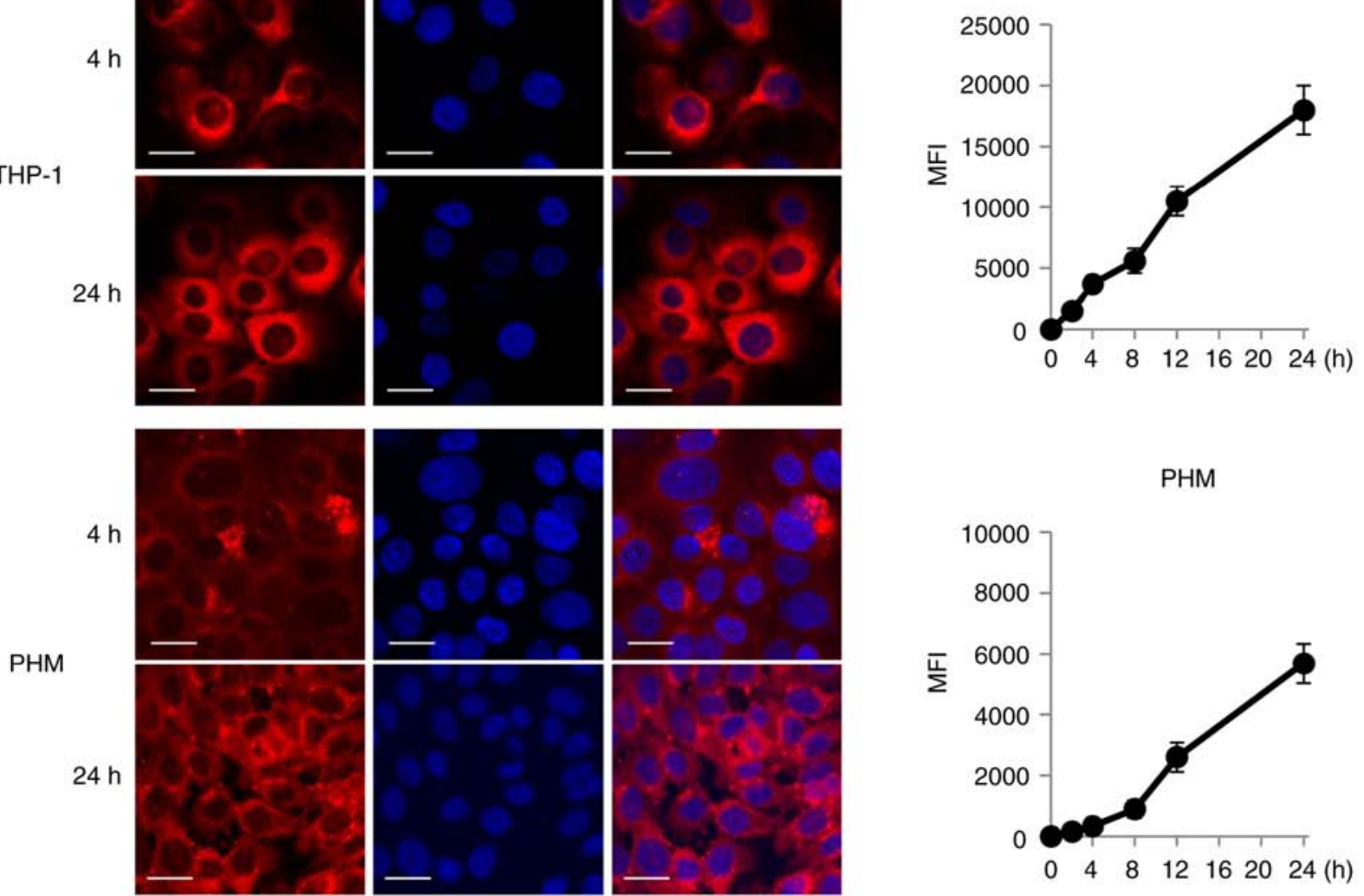

Figure 1. Characterization and cellular internalization of THP-1- and PHM-derived exosomes. (A) TCL and Exo lysates from the THP-1- and PHM-derived exosomes were analyzed by western blotting. (B) OSC-4 cells were incubated in the presence or absence of PKH26-labeled exosomes (red) derived from THP-1 or PHMs cells for 4 and $24 \mathrm{~h}$ and analyzed by confocal microscopy. Nuclei were stained with DAPI (blue) (x400 magnification). Scale bar, $20 \mu \mathrm{m}$. (C) Uptake of the PKH67-labeled THP-1- and PHM-derived exosomes by OSC-4 cells was analyzed by flow cytometry at different time-points. CD9, CD9 antigen; CD63, CD63 antigen; Exo, exosomal; MFI, mean fluorescence intensity; PHM, primary human macrophages; Rab5B, Ras-related protein Rab-5B; TCL, total cell lysate.

The flow cytometric analysis also revealed that there was a time-dependent increase in the uptake of both the PKH67-labeled THP-1- and the PHM-derived exosomes by the OSC-4 cells (Fig. 1C). These data suggested that the macrophage-derived exosomes could be taken up by the OSC-4 cells.
Differential effects of THP-1- and PHM-derived exosomes on proliferation, migration and invasion of the OSC-4 cells. In order to determine the effects of THP-1- and PHM-derived exosomes on the malignant potential of OSCC cells, their effects on the proliferation, migration and invasion of OSC-4 cells were assessed. Both the THP-1- and PHM-derived 

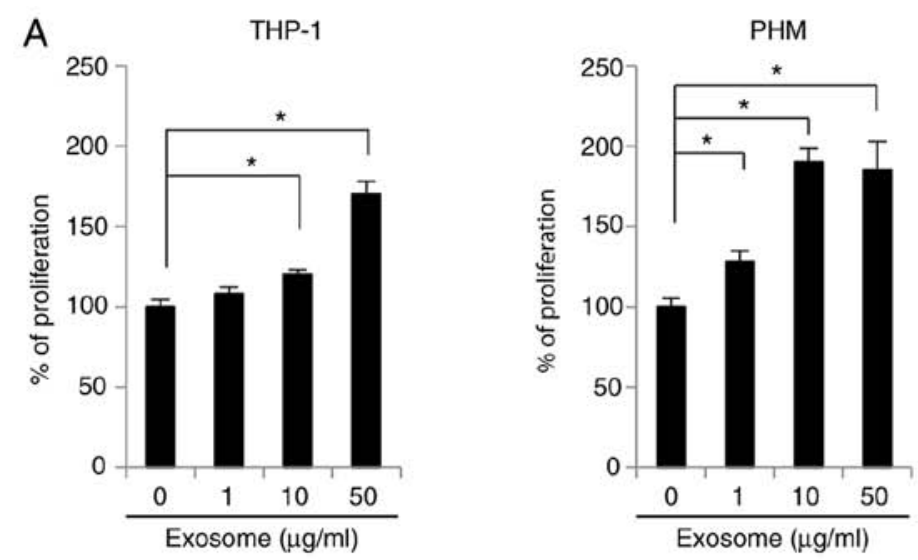

$\mathrm{B}$

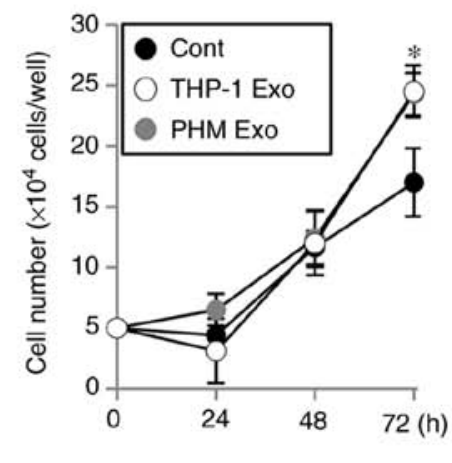

C

THP-1
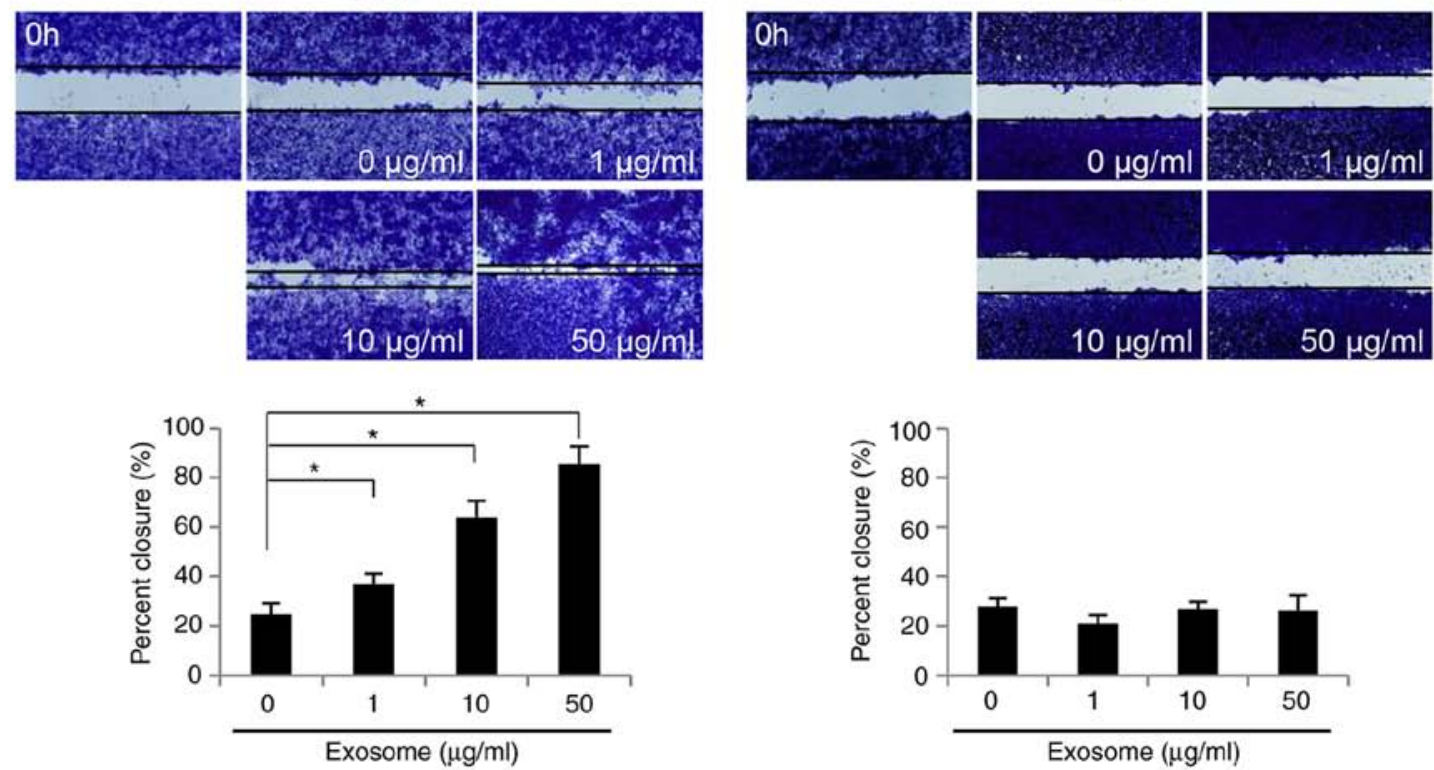

$\mathrm{D}$

THP-1

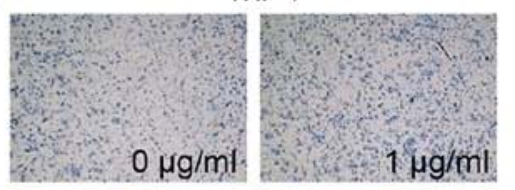

PHM
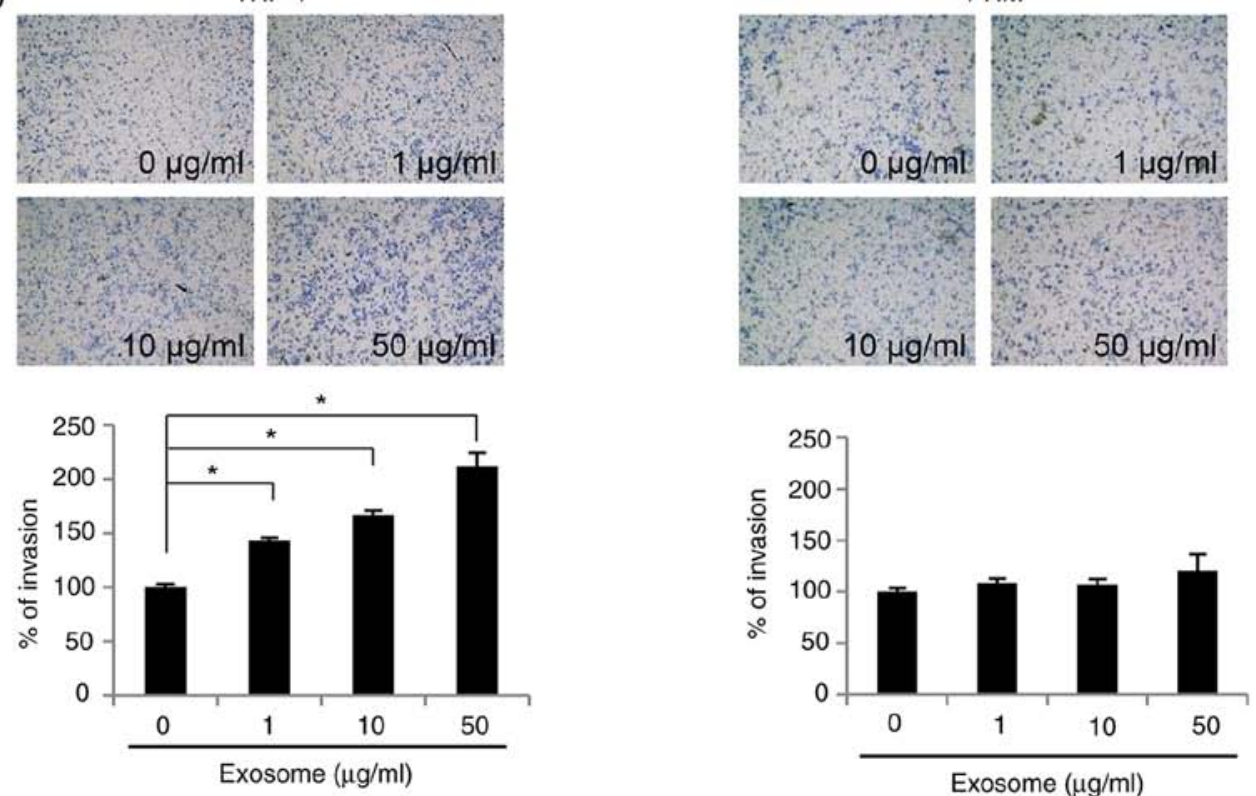

Figure 2. Effects of THP-1- and PHM-derived Exo on proliferation, migration and invasion of OSC-4 cells. OSC-4 cells were incubated in the presence or absence of Exo (1, 10 or $50 \mu \mathrm{g}$ ) for $24 \mathrm{~h}$. The viability was assessed by (A) Cell Counting Kit-8 assay and (B) standard cell counting with a hemocytometer. (C) Wound healing assay to determine the migratory capacity of OSC-4 cells treated with THP-1- and PHM-derived Exo. Magnification, x40. (D) Invasion assay to determine the invasive capacity of OSC-4 cells treated with THP-1- and PHM-derived Exo. Magnification, x100. Data were normalized against exosome $0 \mu \mathrm{g}$. ${ }^{*} \mathrm{P}<0.05$ vs. cells in the absence of Exo. Cont, control; Exo, exosomes; PHM, primary human macrophages. 

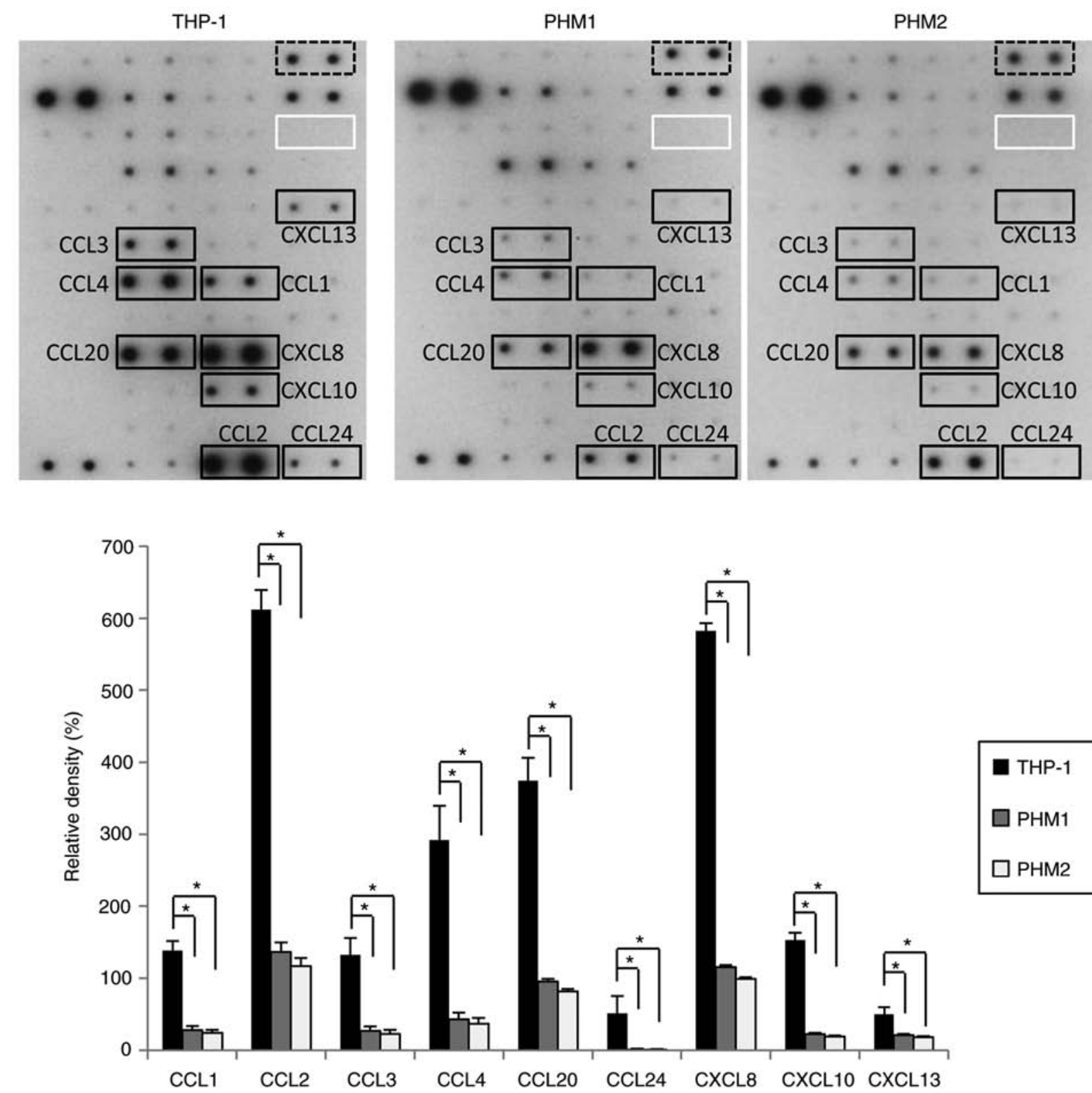

Figure 3. Chemokine array of the THP-1- and PHM-derived exosomes. Chemokine levels for nine representative molecules, which were expressed $>1.5$-fold higher in the THP-1-derived exosomes than in the PHM-derived exosomes, are indicated in black boxes. A positive reference double spots are marked in black dotted boxes, whereas the of negative control is marked in the white rectangle. " $\mathrm{P}<0.05$ vs. THP- 1 exosomes. CCL, C-C motif chemokine ligand; CXCL, C-X-C motif chemokine ligand; PHM, primary human macrophages.

exosomes facilitated proliferation of OSC-4 cells (Fig. 2A). In addition, the cell counting assay demonstrated a significant cell number increase in OSC-4 cells treated with these exosomes at $72 \mathrm{~h}$, compared with the control untreated cells (Fig. 2B). THP-1-derived exosomes also promoted the dose-dependent migration of OSC-4 cells; treatment with $50 \mu \mathrm{g} / \mathrm{ml}$ THP-1-derived exosomes led to approximately $90 \%$ closure of the wound area in the migration assay (Fig. 2C). Furthermore, the increase in the number of OSC- 4 cells invading the Matrigel was dependent on the concentration of the THP-1-derived exosomes (Fig. 2D). Conversely, the PHM-derived exosomes did not exhibit a significant effect on the migration or the invasion of OSC-4 cells, suggesting that the THP-1-derived exosomes were more likely to promote malignancy in the OSC-4 cells compared with the PHM-derived exosomes.
Differences in the protein content of the THP-1- and PHM-derived exosomes. To determine the mechanism underlying the promotion of OSC-4 cell migration and invasion by the THP-1-derived exosomes but not the PHM-derived exosomes, the protein content of the exosomes obtained from the THP-1 cells and PHMs was examined. The expression levels of the chemokines including $\mathrm{C}-\mathrm{C}$ motif chemokine ligand (CCL)-1, CCL-2, CCL-3, CCL-4, CCL-20, CCL-24, C-X-C motif chemokine ligand (CXCL)-8, CXCL-10 and CXCL-13 were $>1.5$ fold higher in the exosomes derived from the THP-1 cells compared with those derived from the PHMs of healthy donors (Fig. 3). These results suggested that the THP-1-derived exosomes contained higher levels of chemokines than the PHM-derived exosomes and that these chemokines might promote the migration and invasion of OSC-4 cells. 
A

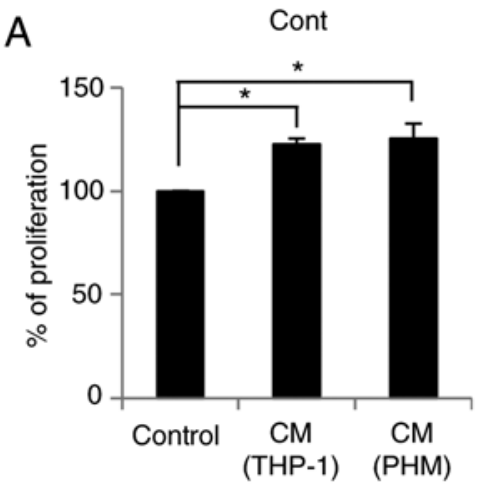

B
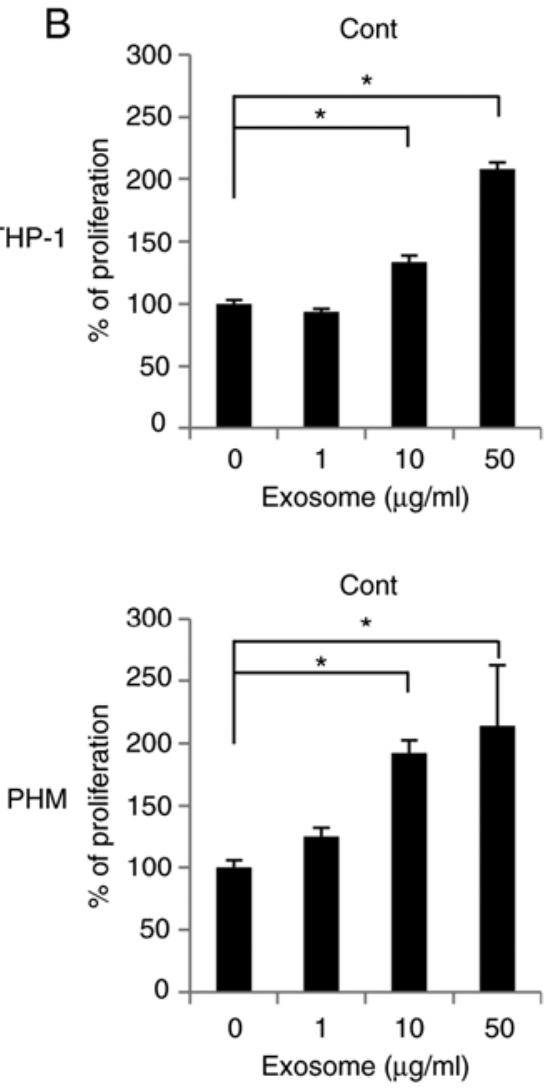
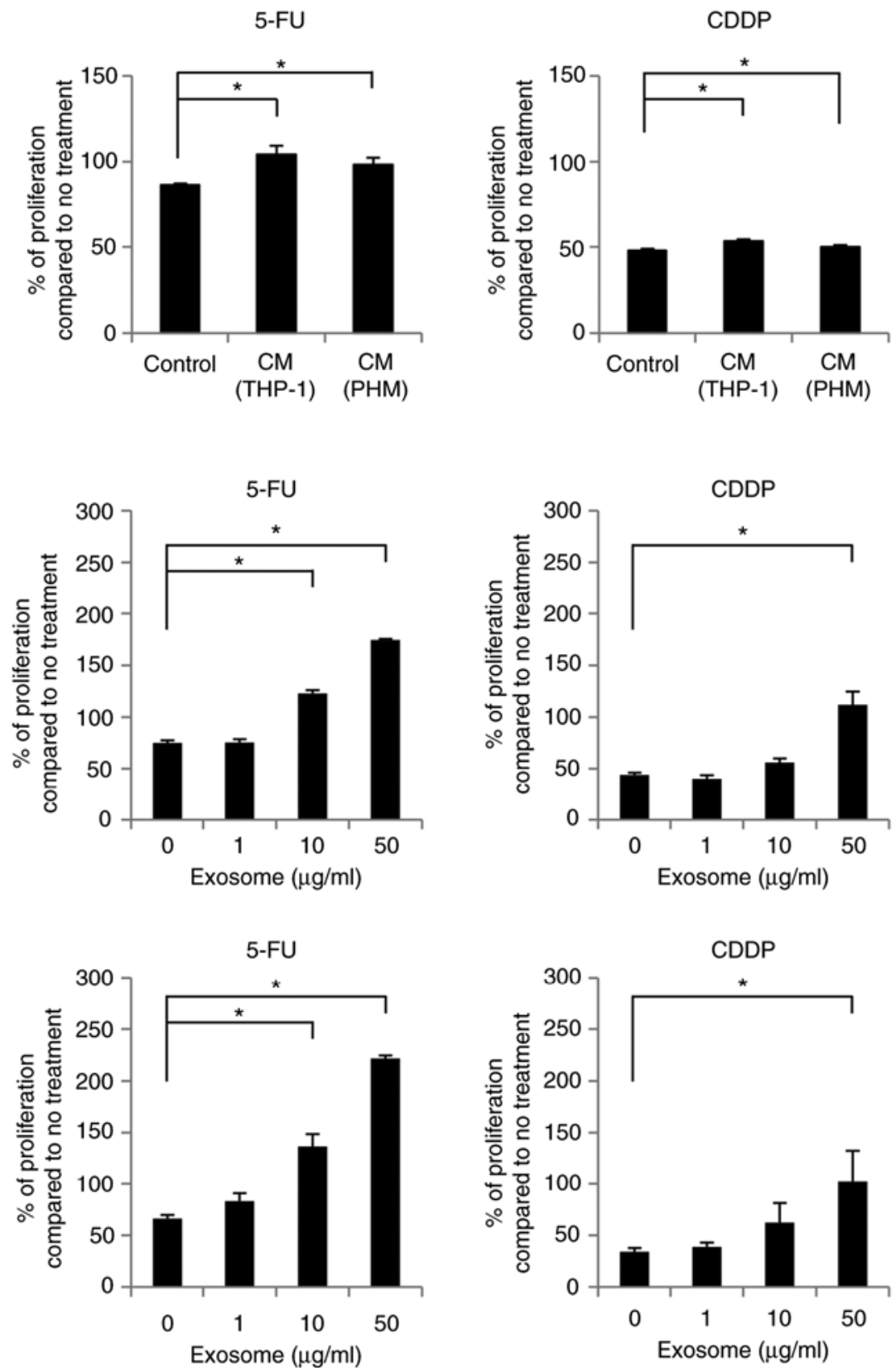

Figure 4. Effects of the THP-1- and PHM-derived exosomes on the sensitivity of OSC-4 cells to chemotherapeutic agents. OSC-4 cells were incubated with (A) CM from THP-1 and PHM cultures or (B) the indicated concentrations of the THP-1- and PHM-derived exosomes for $24 \mathrm{~h}$ in the presence or absence of $100 \mu \mathrm{M} 5$-FU or CDDP, and cell proliferation was assessed with the Cell Counting Kit- 8 assay. " $\mathrm{P}<0.05$ vs. the Cont, that corresponds to cells in the absence of $\mathrm{CM}$ in (A) and exosomes in (B). 5-FU, 5-fluorouracil; CDDP, cis-diamminedichloroplatinum; CM, conditioned medium; Cont, control; PHM, primary human macrophages.

Sensitivity of OSC-4 cells to 5-FU and CDDP is decreased by THP-1- and PHM-derived exosomes. To evaluate the effect of THP-1- and PHM-derived exosomes on the sensitivity of OSC- 4 cells towards chemotherapeutic agents, cell proliferation was measured. OSC-4 cells were treated with the THP-1 and PHM culture supernatants containing exosomes and cells were incubated for $24 \mathrm{~h}$ in the presence or absence of 5-FU or CDDP before performing the CCK-8 assay. The proliferation-promoting effect of THP-1- and PHM-derived isolated exosomes was higher than the culture supernatants (Fig. 4A and B).

Both the THP-1 and PHM culture supernatants attenuated the 5-FU- or CDDP-mediated inhibition of OSC-4 proliferation significantly (Fig. 4A). Similarly, the CCK-8 assay revealed that both the THP-1- and PHM-derived exosomes also suppressed the 5-FU- and CDDP-mediated inhibition of OSC-4 proliferation in a dose-dependent manner and that the treatment of OSC-4 cells with $50 \mu \mathrm{g} / \mathrm{ml}$ exosomes abolished the inhibitory effect of 5-FU and CDDP (Fig. 4B).

Effects of THP-1- and PHM-derived exosomes on cell cycle and apoptosis of OSC-4 cells. In order to determine the effect of THP-1- and PHM-derived exosomes on the cell cycle regulation of OSC-4 cells treated with chemotherapeutic drugs, PI staining was utilized to assess the prevalence of each cell cycle stage. Treatment with 5-FU and CDDP was 

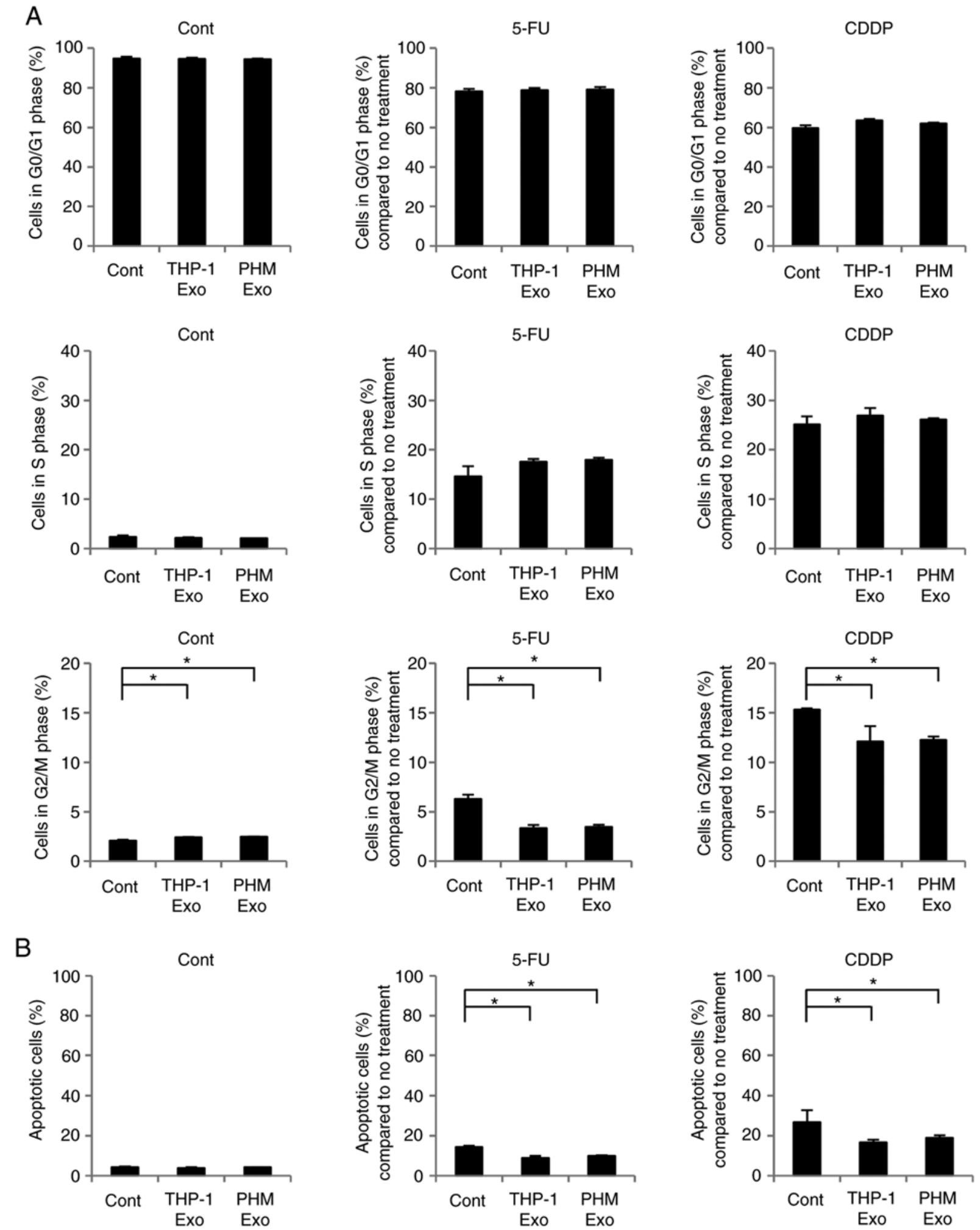

Figure 5. Effects of the THP-1- and PHM-derived Exo on cell cycle regulation and apoptosis in OSC-4 cells. OSC-4 cells were incubated with $50 \mu \mathrm{g} / \mathrm{ml}$ THP-1- and PHM-derived Exo for $24 \mathrm{~h}$ in the presence or absence of $100 \mu \mathrm{M} 5-\mathrm{FU}$ or CDDP, and (A) cell cycle status and (B) apoptosis were evaluated using flow cytometry after the indicated treatments. " $\mathrm{P}<0.05$ vs. the Cont, that corresponds to cells in the absence of Exo. 5-FU, 5-fluorouracil; CDDP, cis-diamminedichloroplatinum; Cont, control; Exo, exosomes; PHM, primary human macrophages.

observed to induce the accumulation of OSC-4 cells in the $\mathrm{S}$ and $\mathrm{G}_{2} / \mathrm{M}$ phases, whereas the addition of the THP-1- or PHM-derived exosomes inhibited the transition of the cells into the G2/M phase (Figs. 5A and S1). Furthermore, the treatment of OSC-4 cells with 5-FU or CDDP increased the percentage of apoptotic cells, which was inhibited by the addition of the THP-1- or PHM-derived exosomes to the cell culture (Figs. 5B and S2). These results suggested that the macrophage-derived exosomes decreased the sensitivity of OSC-4 cells to 5-FU and CDDP through the attenuation of 

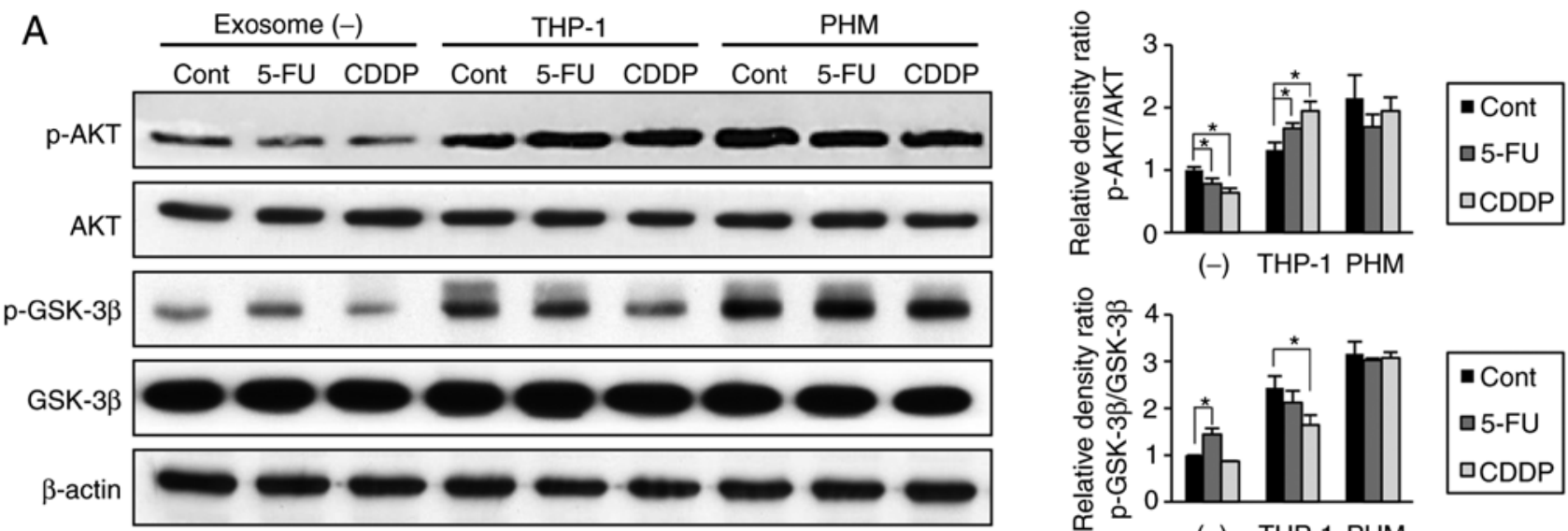

(-) THP-1 PHM

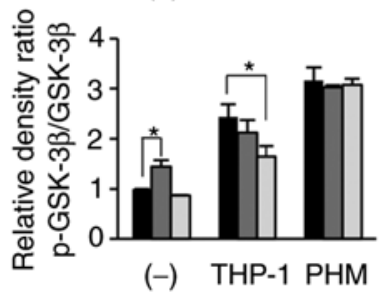

- Cont
$\square 5-F U$
$\square$ CDDP

(-) THP-1 PHM
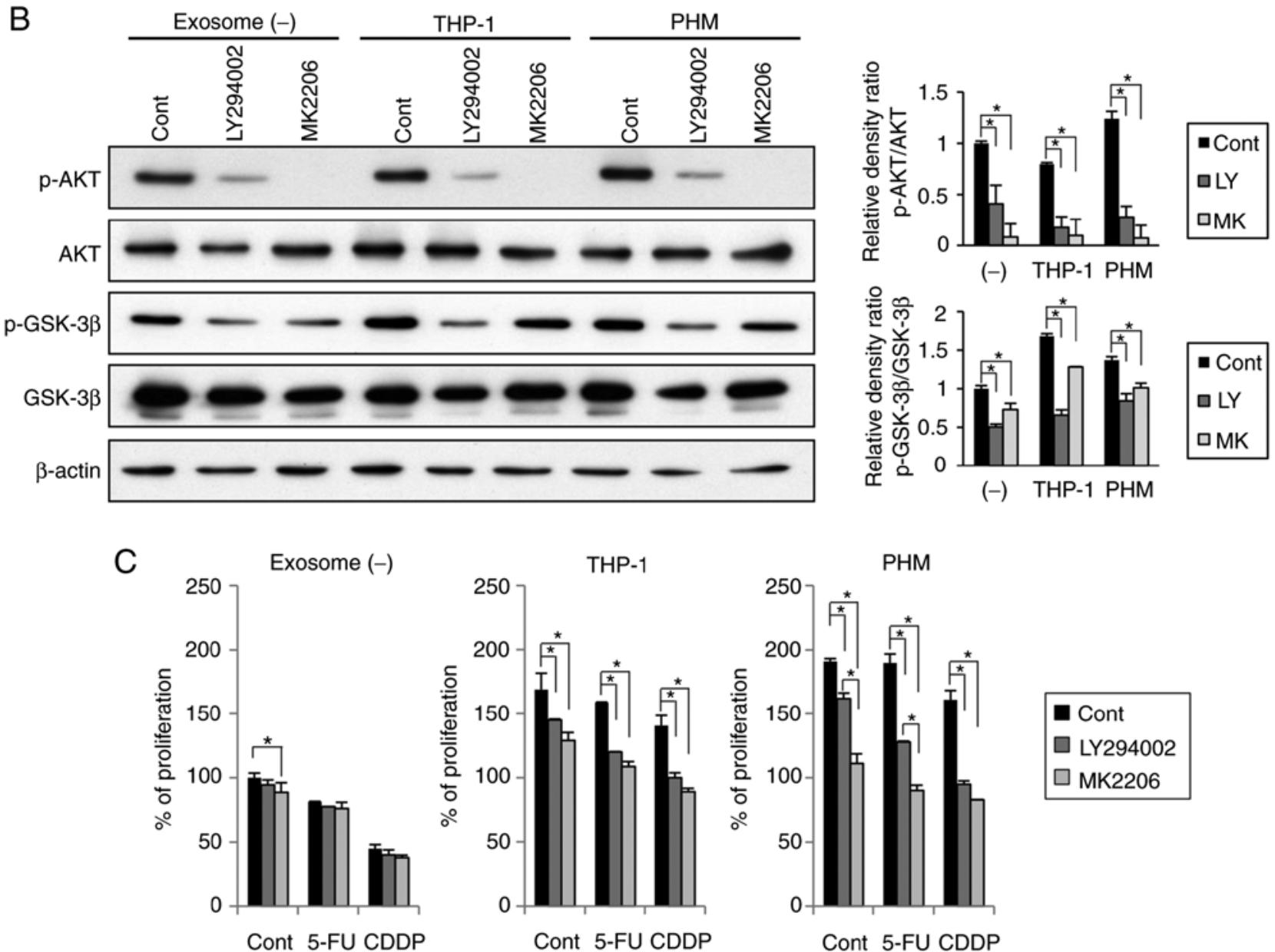

\begin{tabular}{|l|}
\hline$\square$ Cont \\
$\square$ LY294002 \\
$\square$ MK2206 \\
\hline
\end{tabular}

Figure 6. Effects of THP-1- and PHM-derived exosomes on the AKT/GSK-3 $\beta$ signaling pathway in OSC-4 cells. (A) OSC-4 cells were treated with $50 \mu \mathrm{g} / \mathrm{ml}$ THP-1- or PHM-derived exosomes for $24 \mathrm{~h}$ in the presence or absence of $100 \mu \mathrm{M}$ 5-FU or CDDP. (B and C) OSC-4 cells were treated with $10 \mu \mathrm{M}$ LY294002 or $10 \mu \mathrm{M}$ MK-2206 for $24 \mathrm{~h}$ in the presence or absence of $50 \mu \mathrm{g} / \mathrm{ml}$ THP-1 or PHM-derived exosomes. (C) Cell proliferation was measured by the CCK-8 assay. " $\mathrm{P}<0.05$ vs. Cont. 5-FU, 5-fluorouracil; CDDP, cis-diamminedichloroplatinum; Cont, control; GSK-3 $\beta$, glycogen synthase kinase-3 $\beta$; PHM, primary human macrophages.

the effects of the chemotherapeutic agents on cell cycle regulation and apoptosis.

Effects of THP-1- and PHM-derived exosomes on the AKT/GSK-3 $\beta$ signaling pathway in OSC-4 cells. To elucidate the mechanism underlying the attenuation of OSC-4 sensitivity to chemotherapeutic agents by macrophage-derived exosomes, the effects of THP-1- and PHM-derived exosomes on the AKT/GSK-3 $\beta$ signaling pathway were examined. Both, THP-1- and PHM-derived exosomes were found to induce the phosphorylation of AKT as well as GSK-3 $\beta$ in the OSC- 4 cells (Fig. 6A), whereas the treatment with 5-FU or CDDP slightly decreased the phosphorylation levels of AKT and GSK-3 $\beta$. Notably, both the THP-1- and PHM-derived exosomes 
abolished the suppressive effects of 5-FU and CDDP (Fig. 6A). Furthermore, to examine whether these changes could be reversed by PI3K/AKT inhibition, two inhibitors were utilized: LY294002, a PI3K inhibitor and MK-2206, an AKT inhibitor. Both inhibitors were found to decrease the phosphorylation levels of both AKT and GSK-3 $\beta$ in the presence of THP-1- and PHM-derived exosomes (Fig. 6B). In addition, both inhibitors were able to increase the sensitivity of OSC-4 cells to both 5-FU and CDDP drugs in the presence of THP-1- and PHM-derived exosomes (Fig. 6C). These results suggested that the THP-1- and PHM-derived exosomes might reduce the sensitivity of OSC-4 cells to 5-FU and CDDP through the activation of the AKT/GSK-3 $\beta$ signaling pathway.

\section{Discussion}

Infiltrating macrophages in the tumor microenvironment have been reported to promote tumor progression through their interaction with the surrounding cells such as tumor, stromal and immune cells, mediated by the secretion of paracrine factors (4-6). Specifically, TAM infiltration has been reported to be associated with tumor progression and poor prognosis in patients with OSCC (13-15). THP-1 cells differentiated with PMA are widely used as a model to study the function and biology of human macrophages (22). However, THP-1 cells are malignant tumor cells and their characteristics are different from normal macrophages (23). Therefore, the present study used two kinds of macrophages and examined the influence of these cells-derived exosomes on malignant potentials and chemosensitivity of OSCC cells.

The THP-1- and PHM-derived exosomes were rapidly internalized by the OSC-4 cells after their addition to the culture medium and their uptake was time-dependent, which suggested that macrophage-derived exosomes could interact with OSCC cells intimately and could be incorporated into OSCC cells in a very short period of time. Subsequently, to examine the effect of macrophage-derived exosomes on the malignant potential of OSC-4 cells, proliferation, migration and invasion assay were performed. The results demonstrated that both the THP-1- and PHM-derived exosomes promoted the proliferation of OSC-4 cells in a dose-dependent manner. These results coincide with previous studies that reported that macrophage-derived exosomes promoted the progression of various tumors including pancreatic ductal adenocarcinoma, colon cancer and gastric cancer (24-26). However, the exosomes used in those studies were derived from the M2-polarized macrophages induced by exposure to THP-1 cells or primary monocytes treated with $\mathrm{T}$ helper type (Th) 2 cytokines (interleukin (IL)-4 and IL13). In the present study, THP-1 cells or PHMs were not treated with Th1 or Th2 cytokines. Therefore, exosomes derived from macrophages not polarized in M2 may also be able to promote OSCC progression.

Although the THP-1-derived exosomes promoted the migration and invasion of OSC-4 cells, a similar effect was not observed following the exposure of OSC- 4 cells to the PHM-derived exosomes. Therefore, the expression levels of chemokines between the THP-1- and PHM-derived exosomes was analyzed in the present study. A variety of chemokines, including CCL-1, CCL-2, CCL-3, CCL-4, CCL-20, CCL-24, CXCL-8, CXCL-10 and CXCL-13 were highly expressed in the THP-1-derived exosomes compared with the PHM-derived exosomes. Among these chemokines, the expression level of CCL-2 was the highest in the THP-1-derived exosomes. CCL-2 was reported to be secreted by cancer-associated fibroblasts and tumor-associated neutrophils into the tumor microenvironment and was shown to promote the migration and invasion of OSCC cells following bone invasion and lymph node metastasis through the CCL-2/CCR-2 axis (27-31). The stimulatory effects on migration and invasion were also reported for the other chemokines that were highly expressed in the THP-1-derived exosomes, including CCL-4, CCL-20 and CXCL-8 (32-34). From these findings, certain chemokines, contained in large quantities in the THP-1-derived exosomes, may be taken up by OSCC cells and regulate their migration and invasion.

In agreement with studies reporting that TAMs could regulate chemoresistance (7-12), the present study demonstrated the THP-1- and PHM-conditioned medium, as well as the THP-1- and PHM-derived exosomes, were able to decrease the sensitivity of OSC-4 cells to 5-FU and CDDP through the promotion of proliferation, regulation of cell cycle and suppression of apoptosis. These results suggest that, among the TAM-secreted factors, exosomes can be internalized by the OSCC cells to specifically decrease their chemosensitivity. Conversely, previous studies have shown that tumor cell-derived exosomes can also be taken up by macrophages and induce their polarization to an immunosuppressive, M2-like phenotype; upregulate their expression of programmed cell death 1; lead to their accumulation in the tumor microenvironment; promote their secretion of protumoral, bioactive molecules, such as vascular endothelial growth factor, monocyte chemoattractant protein-1, IL-6, IL-1 $\beta$, matrix metalloproteinase-9 and tumor necrosis factor $\alpha$; and lead to altered phagocytosis (35-40). Thus, the communication between macrophages and tumor cells through exosomes may facilitate the progression and metastasis of OSCC.

The AKT/GSK-3 $\beta$ signaling pathway is involved in chemoresistance, epithelial-to-mesenchymal transition (EMT), and cancer stemness (41-43). In the present study, THP-1- and PHM-derived exosomes were demonstrated to result in a marked increase in the levels of p-AKT and p-GSK-3 $\beta$, suggesting that the mechanism underlying the malignant potential and chemoresistance of OSC-4 cells to 5-FU and CDDP potentiated by the THP-1- and PHM-derived exosomes might involve the activation of the AKT/GSK-3 $\beta$ signaling pathway. Some highly expressed chemokines contained in the THP-1 and PHM-derived exosomes are known to be involved in the promotion of cancer progression through the stimulation of the PI3K/AKT signaling pathway. For example, CCL-2 secretion by TAM activated the PI3K/AKT pathway in tumor cells to promote chemoresistance of breast cancer and migration of prostate cancer cells $(44,45)$. CCL-20 secreted by TAM-activated EMT and the migratory ability of renal cell carcinoma cells via AKT activation (46). CXCL-8 derived from macrophages promoted the migration and invasion of esophageal squamous cell carcinoma cells via the phosphorylation of AKT and ERK1/2 through C-X-C motif chemokine receptor (CXCR)-1 and CXCR-2 in vitro (47). These chemokines contained in macrophages-derived exosomes may be associated with the activation of the AKT/GSK- $3 \beta$ signaling 
pathway in OSCC cells. To support this mechanism, PI3K/AKT inhibitors were found to exert significant anticancer effects in the presence of macrophage-derived exosomes. Furthermore, the PI3K/AKT inhibitors LY294002 and wortmannin were previously shown to enhance the CDDP-, 5-FU- and docetaxel-induced apoptosis in OSCC cells (48). The results from the present study suggest that combination therapies, including PI3K/AKT inhibitors and traditional chemotherapeutic agents, may improve the prognosis of patients with OSCC not only by augmenting the OSCC cell apoptosis but also by blocking the inhibitory effects of the TAM-derived exosomes.

In conclusion, the present study provided evidence that macrophage-derived exosomes incorporated into OSCC cells may facilitate chemoresistance through the activation of the AKT/GSK-3 $\beta$ signaling pathway. Further studies are necessary to determine whether TAM-derived exosomes in the tumor microenvironment of OSCC may be a significant factor that can predict chemosensitivity of patients and whether the inhibition of TAM-derived exosomes might be an effective therapeutic strategy.

\section{Acknowledgements}

Not applicable.

\section{Funding}

The present study was partly funded by Grants-in-Aid for Scientific Research from the Ministry of Education, Culture, Sports, Science and Technology of Japan (grant no. 26463012).

\section{Availability of data and materials}

The datasets used and/or analyzed during the present study are available from the corresponding author upon reasonable request.

\section{Authors' contributions}

ES conceived and designed the study. RT and AT performed the experiments. RT wrote the manuscript. TY participated in analyzing the data, performing the statistical analysis and drafting the manuscript. All authors read and approved the final manuscript.

\section{Ethics approval and consent to participate}

The present study was approved by the local Ethics Committee on Medical Research at Kochi Medical School (approval no. 30-107). All blood samples were obtained strictly with the explicit informed consent of all participants of the study. Written informed consent was also obtained from the patient with tongue cancer at the time the sample was taken, and the cell line established.

\section{Patient consent for publication}

Not applicable.

\section{Competing interests}

The authors declare that they have no competing interests.

\section{References}

1. Siegel RL, Miller KD and Jemal A: Cancer statistics, 2018. CA Cancer J Clin 68: 7-30, 2018.

2. Okura M, Aikawa T, Sawai NY, Iida S and Kogo M: Decision analysis and treatment threshold in a management for the NO neck of the oral cavity carcinoma. Oral Oncol 45: 908-911, 2009.

3. Castilho RM, Squarize CH and Almeida LO: Epigenetic modifications and head and neck cancer: Implications for tumor progression and resistance to therapy. Int J Mol Sci 18: 1506, 2017.

4. Kulkarni B, Kirave P, Gondaliya P, Jash K, Jain A, Tekade RK and Kalia K: Exosomal miRNA in chemoresistance, immune evasion, metastasis and progression of cancer. Drug Discov Today 24: 2058-2067. 2019.

5. Ireland LV and Mielgo A: Macrophages and fibroblasts, key players in cancer chemoresistance. Front Cell Dev Biol 6: 131, 2018.

6. Senthebane DA, Rowe A, Thomford NE, Shipanga H, Munro D, Al Mazeedi MAM, Almazyadi HAM, Kallmeyer K, Dandara C, Pepper MS, et al: The role of tumor microenvironment in chemoresistance: To survive, keep your enemies closer. Int J Mol Sci 18: 1586, 2017.

7. Chanmee T, Ontong P, Konno K and Itano N: Tumor-associated macrophages as major players in the tumor microenvironment. Cancers (Basel) 6: 1670-1690, 2014

8. Zhang X, Chen Y, Hao L, Hou A, Chen X, Li Y, Wang R, Luo P, Ruan Z, Ou J, et al: Macrophages induce resistance to 5-fluorouracil chemotherapy in colorectal cancer through the release of putrescine. Cancer Lett 381: 305-313, 2016.

9. Yin Y, Yao S, Hu Y, Feng Y, Li M, Bian Z, Zhang J, Qin Y, Qi X, Zhou L, et al: The immune-microenvironment confers chemoresistance of colorectal cancer through macrophage-derived IL6. Clin Cancer Res 23: 7375-7387, 2017.

10. Zheng P, Chen L, Yuan X, Luo Q, Liu Y, Xie G, Ma Y and Shen L: Exosomal transfer of tumor-associated macrophage-derived miR-21 confers cisplatin resistance in gastric cancer cells. J Exp Clin Cancer Res 36: 53, 2017.

11. Wei C, Yang C, Wang S, Shi D, Zhang C, Lin X and Xiong B: M2 macrophages confer resistance to 5-fluorouracil in colorectal cancer through the activation of CCL22/PI3K/AKT signaling. Onco Targets Ther 12: 3051-3063, 2019.

12. Perrotta C, Cervia D, Di Renzo I, Moscheni C, Bassi MT, Campana L, Martelli C, Catalani E, Giovarelli M, Zecchini S, et al: Nitric oxide generated by tumor-associated macrophages is responsible for cancer resistance to cisplatin and correlated with syntaxin 4 and acid sphingomyelinase inhibition. Front Immunol 9: 1186, 2018

13. Troiano G, Caponio VCA, Adipietro I, Tepedino M, Santoro R, Laino L, Lo Russo L, Cirillo N and Lo Muzio L: Prognostic significance of $\mathrm{CD} 68^{+}$and $\mathrm{CD} 163^{+}$tumor associated macrophages in head and neck squamous cell carcinoma: A systematic review and meta-analysis. Oral Oncol 93: 66-75, 2019.

14. Kubota K, Moriyama M, Furukawa S, Rafiul HASM, Maruse Y, Jinno T, Tanaka A, Ohta M, Ishiguro N, Yamauchi M, et al: $\mathrm{CD}_{163}{ }^{+} \mathrm{CD} 204^{+}$tumor-associated macrophages contribute to $\mathrm{T}$ cell regulation via interleukin-10 and PD-L1 production in oral squamous cell carcinoma. Sci Rep 7: 1755, 2017.

15. Hu Y, He MY, Zhu LF, Yang CC, Zhou ML, Wang Q, Zhang W, Zheng YY, Wang DM, Xu ZQ, et al: Tumor-associated macrophages correlate with the clinicopathological features and poor outcomes via inducing epithelial to mesenchymal transition in oral squamous cell carcinoma. J Exp Clin Cancer Res 35: 12, 2016.

16. Raposo G and Stoorvogel W: Extracellular vesicles: Exosomes, microvesicles, and friends. J Cell Biol 200: 373-383, 2013.

17. Vlassov AV, Magdaleno S, Setterquist R and Conrad R: Exosomes: Current knowledge of their composition, biological functions, and diagnostic and therapeutic potentials. Biochim Biophys Acta 1820: 940-948, 2012.

18. Mathivanan S, Ji H and Simpson RJ: Exosomes: Extracellular organelles important in intercellular communication. J Proteomics 73: 1907-1920, 2010.

19. Bang $C$ and Thum T: Exosomes: New players in cell-cell communication. Int J Biochem Cell Biol 44: 2060-2064, 2012. 
20. Sento S, Sasabe E and Yamamoto T: Application of a persistent heparin treatment inhibits the malignant potential of oral squamous carcinoma cells induced by tumor cell-derived exosomes. PLoS One 11: e0148454, 2016.

21. Osaki T, Tatemoto Y, Yoneda K and Yamamoto T: Tumorigenicity of cell lines established from oral squamous cell carcinoma and its metastatic lymph nodes. Eur J Cancer B Oral Oncol 30B: 296-301, 1994

22. Chanput W, Mes JJ and Wichers HJ: THP-1 cell line: An in vitro cell model for immune modulation approach. Int Immunopharmacol 23: 37-45, 2014

23. Daigneault M, Preston JA, Marriott HM, Whyte MK and Dockrell DH: The identification of markers of macrophage differentiation in PMA-stimulated THP-1 cells and monocyte-derived macrophages. PLoS One 5: e8668, 2010.

24. Yin Z, Ma T, Huang B, Lin L, Zhou Y, Yan J, Zou Y and Chen S: Macrophage-derived exosomal microRNA-501-3p promotes progression of pancreatic ductal adenocarcinoma through the TGFBR3-mediated TGF- $\beta$ signaling pathway. J Exp Clin Cancer Res 38: 310, 2019.

25. Lan J, Sun L, Xu F, Liu L, Hu F, Song D, Hou Z, Wu W, Luo X, Wang J, et al: M2 macrophage-derived exosomes promote cell migration and invasion in colon cancer. Cancer Res 79: 146-158, 2019.

26. Zheng P, Luo Q, Wang W, Li J, Wang T, Wang P, Chen L, Zhang P, Chen $\mathrm{H}$, Liu Y, et al: Tumor-associated macrophages-derived exosomes promote the migration of gastric cancer cells by transfer of functional apolipoprotein E. Cell Death Dis 9: 434, 2018.

27. Li X, Xu Q, Wu Y, Li J, Tang D, Han L and Fan Q: A CCL2/ROS autoregulation loop is critical for cancer-associated fibroblasts-enhanced tumor growth of oral squamous cell carcinoma. Carcinogenesis 35: 1362-1370, 2014.

28. Wu MH, Hong HC, Hong TM, Chiang WF, Jin YT and Chen YL: Targeting galectin-1 in carcinoma-associated fibroblasts inhibits oral squamous cell carcinoma metastasis by downregulating MCP-1/CCL2 expression. Clin Cancer Res 17: 1306-1316, 2011.

29. Quan J, Morrison NA, Johnson NW and Gao J: MCP-1 as a potential target to inhibit the bone invasion by oral squamous cell carcinoma. J Cell Biochem 115: 1787-1798, 2014.

30. Fujita S and Ikeda T: The CCL2-CCR2 axis in lymph node metastasis from oral squamous cell carcinoma: An immunohistochemical study. J Oral Maxillofac Surg 75: 742-749, 2017.

31. Ku WT, Tung JJ, Lee TJ and Lai KC: Long-term exposure to Oroxylin A inhibits metastasis by suppressing CCL2 in oral squamous cell carcinoma cells. Cancers (Basel) 11: E353, 2019.

32. Lu H, Wu B, Ma G, Zheng D, Song R, Huang E, Mao M and $\mathrm{Lu}$ B: Melatonin represses oral squamous cell carcinoma metastasis by inhibiting tumor-associated neutrophils. Am J Transl Res 9: 5361-5374, 2017.

33. Chen CH, Chuang HC, Lin YT, Fang FM, Huang CC, Chen CM, Lu H and Chien CY: Circulating CD105 shows significant impact in patients of oral cancer and promotes malignancy of cancer cells via CCL20. Tumour Biol 37: 1995-2005, 2016.

34. Christofakis EP, Miyazaki H, Rubink DS and Yeudall WA Roles of CXCL8 in squamous cell carcinoma proliferation and migration. Oral Oncol 44: 920-926, 2008.

35. Linton SS, Abraham T, Liao J, Clawson GA, Butler PJ, Fox T, Kester M and Matters GL: Tumor-promoting effects of pancreatic cancer cell exosomes on THP-1-derived macrophages. PLoS One 13: e0206759, 2018.

36. Chen X, Zhou J, Li X, Wang X, Lin Y and Wang X: Exosomes derived from hypoxic epithelial ovarian cancer cells deliver microRNAs to macrophages and elicit a tumor-promoted phenotype. Cancer Lett 435: 80-91, 2018.
37. Hsieh $\mathrm{CH}$, Tai SK and Yang MH: Snail-overexpressing cancer cells promote M2-like polarization of tumor-associated macrophages by delivering MiR-21-abundant exosomes. Neoplasia 20: 775-788, 2018.

38. Wang X, Luo G, Zhang K, Cao J, Huang C, Jiang T, Liu B, Su L and Qiu Z: Hypoxic tumor-derived exosomal miR-301a mediates M2 macrophage polarization via PTEN/PI3K $\gamma$ to promote pancreatic cancer metastasis. Cancer Res 78: 4586-4598, 2018.

39. Wang F, Li B, Wei Y, Zhao Y, Wang L, Zhang P, Yang J, He W, Chen $\mathrm{H}$, Jiao $\mathrm{Z}$ and Li Y: Tumor-derived exosomes induce PD1 ${ }^{+}$ macrophage population in human gastric cancer that promotes disease progression. Oncogenesis 7: 41, 2018.

40. Piao YJ, Kim HS, Hwang EH, Woo J, Zhang M and Moon WK: Breast cancer cell-derived exosomes and macrophage polarization are associated with lymph node metastasis. Oncotarget 9: 7398-7410, 2017.

41. Namba T, Kodama R, Moritomo S, Hoshino T and Mizushima T: Zidovudine, an anti-viral drug, resensitizes gemcitabine-resistant pancreatic cancer cells to gemcitabine by inhibition of the Akt-GSK3ß-Snail pathway. Cell Death Dis 6: e1795, 2015.

42. Matsumoto T, Yokoi A, Hashimura M, Oguri Y, Akiya M and Saegusa M: TGF- $\beta$-mediated LEFTY/Akt/GSK-3 $\beta /$ Snail axis modulates epithelial-mesenchymal transition and cancer stem cell properties in ovarian clear cell carcinomas. Mol Carcinog 57: 957-967, 2018.

43. Meng Q, Shi S, Liang C, Liang D, Hua J, Zhang B, Xu J and Yu X: Abrogation of glutathione peroxidase-1 drives EMT and chemoresistance in pancreatic cancer by activating ROS-mediated Akt/GSK3 $\beta /$ Snail signaling. Oncogene 37: 5843-5857, 2018.

44. Li D, Ji H, Niu X, Yin L, Wang Y, Gu Y, Wang J, Zhou X, Zhang $\mathrm{H}$ and Zhang Q: Tumor-associated macrophages secrete CC-chemokine ligand 2 and induce tamoxifen resistance by activating $\mathrm{PI} 3 \mathrm{~K} / \mathrm{Akt} / \mathrm{mTOR}$ in breast cancer. Cancer Sci 111: 47-58, 2020.

45. Maolake A, Izumi K, Shigehara K, Natsagdorj A, Iwamoto H, Kadomoto S, Takezawa Y, Machioka K, Narimoto K, Namiki M, et al: Tumor-associated macrophages promote prostate cancer migration through activation of the CCL22-CCR4 axis. Oncotarget 8: 9739-9751, 2017.

46. Kadomoto S, Izumi K, Hiratsuka K, Nakano T, Naito R, Makino T, Iwamoto H, Yaegashi H, Shigehara K, Kadono Y, et al: Tumor-associated macrophages induce migration of renal cell carcinoma cells via activation of the CCL20-CCR6 axis. Cancers (Basel) 12: 89, 2019.

47. Hosono M, Koma YI, Takase N, Urakawa N, Higashino N, Suemune K, Kodaira H, Nishio M, Shigeoka M, Kakeji Y and Yokozaki H: CXCL8 derived from tumor-associated macrophages and esophageal squamous cell carcinomas contributes to tumor progression by promoting migration and invasion of cancer cells. Oncotarget 8: 106071-106088, 2017.

48. Iwase M, Yoshiba S, Uchid M, Takaoka S, Kurihara Y, Ito D, Hatori M and Shintani S: Enhanced susceptibility to apoptosis of oral squamous cell carcinoma cells subjected to combined treatment with anticancer drugs and phosphatidylinositol 3-kinase inhibitors. Int J Oncol 31: 1141-1147, 2007.

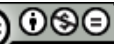

This work is licensed under a Creative Commons Attribution-NonCommercial-NoDerivatives 4.0 International (CC BY-NC-ND 4.0) License. 